\section{Diseño de soluciones químicas para la extracción de ácido desoxirribonucleico en productos biotecnológicos*}

\section{Design of chemical solutions for extraction of deoxyribonucleic acid in biotechnological products}

\author{
Lázaro Núñez Cárdenas**
}

** MsC.; Instituto Nacional de Higiene, Epidemiología y Microbiología de Cuba. Laboratorio de detección de Organismos Genéticamente Modificados en alimentos. lanuca35@gmail.com. Avenida Infanta 1159 entre Llinas y Clavel. Centro Habana. La Habana. Cuba.CP: 10400.

\section{Resumen}

Una de las técnicas utilizadas para la identificación de los organismos genéticamente modificados o transgénicos, es la reacción en cadena de la polimerasa. Para ello, se extrae de la muestra de interés, el ácido desoxirribonucleico con calidad amplificable y a concentraciones adecuadas; mediante el empleo de métodos químico-físicos, mecánicos o enzimáticos. Sin embargo, para la obtención de mejores resultados, se realiza la combinación de estos métodos. Tal es el caso del procedimiento basado en el uso del detergente catiónico bromuro de cetil trimetil amonio; ampliamente reportado en literatura temática. Con el objetivo de obtener alternativas al uso de este reactivo, para la extracción de ácido desoxirribonucleico, se diseñaron nuevas variantes; que combinan el uso de sustancias químicas como: Urea, Guanidio, Tween 20, Sarcosil y Dodecil Sulfato de Sodio y se siguieron los procedimientos establecidos para la extracción de ácidos nucleicos según el método CTAB. Al comparar los valores de las concentraciones de ácido nucleico extraído de las muestras de arroz, trigo, maíz, soya, tabaco y plátano, se obtienen concentraciones similares de ácido desoxirribonucleico de calidad amplificable, en los métodos diseñados, respecto al método que emplea Bromuro de cetil trimetil amonio. Sin embargo, al realizar un análisis económico, se determinó que con la aplicación de urea y Dodecil Sulfato de Sodio, se obtiene un ahorro económico del $48.3 \%$ en costo de reactivos; equivalente a 0.5 dólar por cada muestra analizada. Estos resultados manifiestan, la posibilidad de emplear métodos alternativos, al CTAB, para la extracción de ácido desoxirribonucleico en matrices complejas.

Palabras clave: Ácido desoxirribonucleico, CTAB, detergentes, transgénicos.
Recibido: $28 / 03 / 2016$

Revisado: 09/05/2016

Aceptado: 25/11/2016

Correspondencia de autor: lanuca35@gmail.com

(C) 2016 Universidad La Gran Colombia. Este es un artículo de acceso abierto, distribuido bajo los términos de la licencia Creative Commons Attribution License, que permite el uso ilimitado, distribución y reproducción en cualquier medio, siempre que el autor original y la fuente se acrediten.

* Laboratorio de detección de Organismos Genéticamente Modificados en alimentos. Instituto Nacional de Higiene, Epidemiología y Microbiología de Cuba.

Cómo citar:

Nuñez. C, L. (2016)Diseño de soluciones químicas para la extracción de ácido desoxirribonucleico en productos biotecnológicos, UGCiencia 22, 37-44.

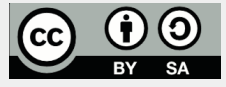




\begin{abstract}
One of the techniques used to identify organisms genetically modified or transgenic, is polymerase chain reaction. For such purpose, the deoxyribonucleic acid of extendable quality and at proper concentrations is collected from the sample, through chemo-physical, mechanic or enzymatic methods. However, to achieve better results, such methods may be combined. Such in the case of the procedure based on the Cationic detergent cetyl trimethyl ammonium bromide, widely reported in literature. In order to obtain alternatives to the use of this reagent to extract deoxyribonucleic acid, new variants were designed, which combine the use of chemical substances, such as: Urea, Guanidium, Tween 20, Sarcosyl and Sodium Dodecyl Sulfate, and procedures established to extract nucleic acids, according to CTAB methods were followed. At comparing values of nucleic acid concentrations, extracted from rice, wheat, corn, soy, tobacco and banana, similar concentrations of deoxyribonucleic acid of expandable quality are obtained, in designed methods, regarding the method which uses Cetyl trimethyl ammonium bromide. However, an economic analysis determined that through application of Urea and sodium dodecyl sulfate, an economic savings of $48.3 \%$ in reagent cost is achieved, which is equal to 0.5 dollar, per analyzed sample. These results show the possibility of using alternative methods to $\mathrm{CTAB}$, for extraction of deoxyribonucleic acid in complex matrixes.
\end{abstract}

Key words: Deoxyribonucleic acid, CTAB, detergents, transgenic.

\title{
Introducción
}

La búsqueda de alternativas para la obtención de métodos de purificación y extracción de ácido desoxirribonucleico (ADN) con elevada pureza, concentración y bajos costos económicos, ha permitido el desarrollo de una amplia variedad de protocolos. (Bartlett \& Stirling, 2003) (Roux, K.H, 1995) (Rott, M, 2004). Sin embargo, los fundamentos químico-físicos establecidos para la obtención del ADN, siguen siendo los mismos y sólo varían en dependencia del tipo sustancias químicas a utilizar (Querci M. 2007) (Anklam, 2002), orden de aplicación de los procedimientos, niveles de concentración de los reactivos, entre otros aspectos. (Holst-Jensen, 2003) (Margarit, 2006)

Para la obtención del ácido desoxirribonucleico es necesario lograr la ruptura de la membrana celular y de esta forma tener acceso al material nuclear. Para ello, se requiere alcanzar la mayor cantidad de ADN, extraído con el mínimo nivel de degradación. Lo cual permitirá llevar a cabo la reacción en cadena de la polimerasa y de esta forma lograr la amplificación del segmento de gen genéticamente modificado. Esta técnica

de biología molecular fue descrita en 1986 por Kary Mullis (Mullis, 1990) y se refiere a la amplificación enzimática de un fragmento de ácido nucleico que actúa como fragmento original o molde y constituye el principal método de detección de los transgénicos, a partir de las modificaciones hechas en el ADN nativo. (Holst-Jensen, 2003). (Ovesná J, 2010).

Uno de estos métodos se basa en el uso del detergente catiónico bromuro de cetil trimetil amonio (CTAB), capaz de formar micelas con los lípidos de la membrana celular y de esta forma, provocar la ruptura de la célula y liberación de los componentes que se encuentran en su interior. Este detergente también es usado en la síntesis de soluciones antisépticas y en la síntesis de nanopartículas de oro; pero tiene como gran desventaja su alto costo económico.

Otra forma de penetrar al interior de la célula y obtener los ácidos nucleicos, es mediante el uso de agentes químicos tales como: sustancias caotrópicos (Urea, Guanidio), detergentes (Tween 20, Sarcosil, Dodecil sulfato de sodio), 
agentes enzimáticos (proteinasa $\mathrm{K}$ ) y mediante el uso de métodos mecánicos. (Núñez, 2011), (Tripathi, 2005), (Jasbeer, 2009), (Corbisier, 2007). (Tozzini, 2004).

De todas estas variantes las más usadas son las enzimáticas y las que combinan el empleo de agentes caotrópicos; caracterizados por su elevada variabilidad de uso y costos económicos accesibles. (Tripathi, 2005), (Porcar, 2007). Como objetivo de nuestro estudio, se diseñaron diversas combinaciones de los reactivos mencionados y se evaluó la capacidad de extracción de ácido desoxirribonucleico, en muestras de maíz, soya, trigo, arroz y tabaco en cada una de las variantes empleadas.

\section{Materiales y métodos}

\section{Muestras}

Se utilizó como material de referencia: granos de soya transgénica $\mathrm{C}-\mathrm{IL} 1$, granos de maíz transgénico BT-1507 y granos de maíz no transgénico de la variedad cubana FR-28, provenientes del Centro de Ingeniería Genética y Biotecnología de La Habana. Las muestras de granos de trigo, granos de arroz, hojas de plátano y hojas de tabaco fueron obtenidas de la red de comercio minorista de ciudad de La Habana. Las muestras fueron molinadas para su uso y el análisis de las mismas, se realizó por triplicado.

\section{Reactivos}

Se utilizó Cloroformo (Riedel-de Haen, Alemania), Etanol (Riedel-de Haen, Alemania), Acetato de Amonio (Merck, Darmstadt, Alemania), Urea (Sigma, EE.UU.) Acido Etilen diamino tetracetico (EDTA) (Sigma, EE.UU.), Tris-HCL (Merck, Darmstadt, Alemania), Cloruro de Sodio (Sigma, EE.UU.), Isopropanol (Merck, Darmstadt, Alemania), Agarosa (Sigma
St. Louis, MI, USA), CTAB (Invitrogen, USA), Proteinasa K (Invitrogen, USA), RNA asa, (Sigma, USA).

\section{Extracción y purificación de ADN genómico}

Para el método CTAB se siguió el procedimiento descrito en el manual de formación “ Análisis de la presencia de organismos genéticamente modificados en muestras de alimentos " (Querci M, 2007, 50-60). El procedimiento seguido, para la extracción de ácido desoxirribonucleico según las nuevas soluciones diseñadas, se muestra en la figura 1. Todas las soluciones de extracción se ajustaron a $\mathrm{pH} 8 \pm 0.1$ con solución HCL $7 \mathrm{~N}$.

\section{Cuantificación del ADN}

La concentración de ácido desoxirribonucleico extraído se determinó por absorbancia a 260 $\mathrm{nm}$ en un espectrofotómetro modelo Nano Drop 1000 V3.7.1, (Ee.uu.), con capacidad de análisis de $1 \mu \mathrm{L}$ de muestra. La calidad del ácido desoxirribonucleico extraído, se determinó por la relación de absorbancia 260/280, con rango de aceptación de 1.8-2.0.

\section{Condiciones de la reacción en cadena de la polimerasa (PCR)}

Se utilizó un termociclador TC-PRO (Boeco, Alemania). La mezcla de reacción utilizada consistió en: Tampón STR (Promega, EE.UU.) 1X, dNTP 200 $\mathrm{MM}$, 20pmoles de los cebadores específicos, Taq Polimerasa (Enzibiot, Heber-Biotec, Cuba) y agua para cada determinación. Se adicionaron $24 \mu \mathrm{L}$ de la mezcla de reacción a viales de $0.5 \mathrm{~mL}$ que contenían 50ng de ácido desoxirribonucleico genómico, correspondiente a cada una de las preparaciones. Las mezclas de reacción se calentaron a $95^{\circ} \mathrm{C}$ por 5 minutos. Posteriormente 
se siguió el siguiente programa de amplificación: $95^{\circ} \mathrm{C}$ por 30 seg., $60^{\circ} \mathrm{C}$ por 45 seg., $72^{\circ} \mathrm{C}$ por 1 min., (por 40 ciclos). Finalmente, se realizó un paso de extensión a $72^{\circ} \mathrm{C}$ por otros $10 \mathrm{~min}$. Las reacciones de PCR se realizaron por duplicado y fueron analizadas en una electroforesis de ácido desoxirribonucleico en geles de agarosa al $2 \%$.

\section{Oligonucleótidos}

Para amplificar un fragmento de ácido desoxirribonucleico de $123 \mathrm{pb}$, correspondiente a la secuencia del promotor $35 \mathrm{~S}$ del Virus Mozaico de la Coliflor (CAMV 35S) (AF294982), se utilizó el siguiente juego de oligos:

\section{5' CCA CGT CTT CAA AGC AAG TGG 3' 21 bases}

\section{5' TCC TCT CCA AAT GAA ATG AAC TTC C 3' 25 bases.}

\section{Electroforesis en geles de agarosa}

Se empleó un equipo electroforesis power supply EPS 500/400 de Pharmacia Fine Chemical. Las corridas cromatográficas se realizaron en geles de 0.8 y $2 \%$ de concentración de agarosa en presencia de la sustancia intercalante Bromuro de etidio, a una concentración de $10 \mathrm{mg} / \mathrm{mL}$. Las corridas cromatográficas se realizaron en tampón Borato tris EDTA (Querci M. and col, 2007, 60-70)) a 100 V durante 60 minutos. Los patrones de peso molecular utilizados fueron: Landa ácido desoxirribonucleico / HINd III Markers y Landa $100 \mathrm{pb}$. Ladder de Promega Madisson. W. (EE.UU.) Para el análisis se aplicó una concentración de $50 \mathrm{ng} / \mu \mathrm{L}$ de ácido desoxirribonucleico por pozo.

\section{Costos económicos de los métodos desarrollados}

Se calculó el valor económico de los reactivos comunes para ambos métodos, necesarios para el análisis de 250 muestras (100 mg por muestra) se determinó mediante el siguiente cálculo:

$\mathrm{CRM}=(\mathrm{CRC}+\mathrm{CRE}) / 250$

Donde: $\mathrm{CRM}=$ Costo reactivos para análisis de 1 muestra; $\mathrm{CRC}=$ costo reactivos comunes para ambos métodos; CRE $=$ costo reactivos específicos por método.

\section{Resultados}

La efectividad de los métodos: " W ", " X ", " Y " y " Z", se determinó a partir de la extracción de ácido desoxirribonucleico en muestras de maíz (figura 1); utilizando el método CTAB, como control positivo de la extracción. En todos los casos, se obtuvieron cantidades similares de concentración de ácido desoxirribonucleico, con adecuada pureza (tabla 1), determinada por la relación de absorbancia ácido desoxirribonucleico /proteína $(260 / 280 \mathrm{~nm})$ y con valores de aceptación entre 1.8 y 2.0.

Figura 1. Esquema seguido para la extracción y purificación de ADN usando las nuevas formulaciones.

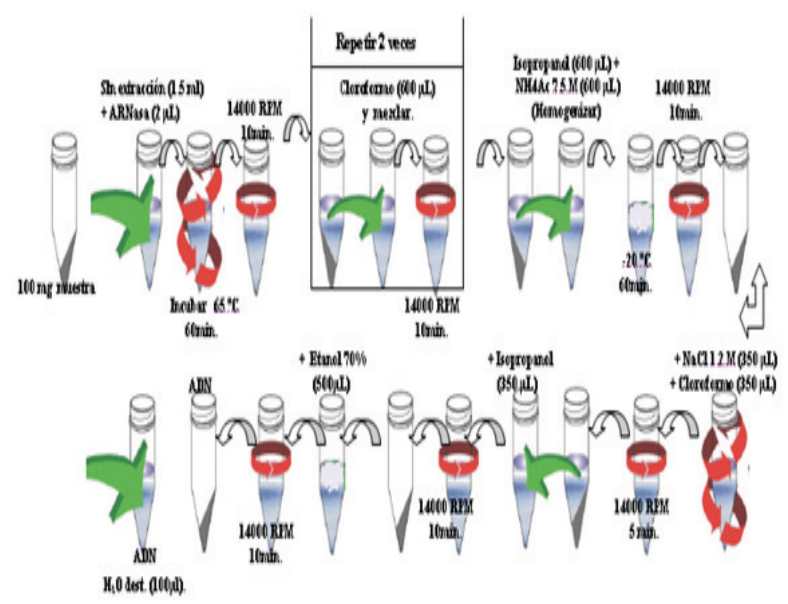


Tabla 1. Cuantificación y determinación de la calidad del ADN, extraído de muestras de Maíz, a partir del uso de los diferentes métodos.

\begin{tabular}{lll}
\hline Métodos & $\mathbf{n g} / \mathbf{u l}$ & $\mathbf{2 6 0 / 2 8 0}$ \\
\hline W (Tween 20, NaCl, Tris-HCL, EDTA, Urea) & $177.69 \pm 9.10$ & $1.69 \pm 0.019$ \\
X (Tween 20, NaCl, Tris-HCL, EDT A, Urea, Sarcosil) & $119.15 \pm 6.83$ & $1.78 \pm 0.029$ \\
Y (Sarcosil, NaCl, Tris-HCL, EDT A, Urea,) & $205.73 \pm 11.3$ & $1.85 \pm 0.021$ \\
Z (SDS, NaCl, Tris-HCL, EDTA, Urea). & $258.18 \pm 8.41$ & $1.86 \pm 0.024$ \\
CTAB & $274.25 \pm 7.32$ & $1.93 \pm 0.016$ \\
\hline
\end{tabular}

El ácido desoxirribonucleico extraído de las muestras transgénicas de maíz BT-1507 y soya C-IL1, las cuales presentan en su casete de inserción un fragmento del gen promotor p35S, fue utilizado para evaluar la calidad amplificable del ADN. En la Figura 2. A. se muestran los resultados de la electroforesis en un gel de 2 $\%$; producto de la amplificación del ADN, en el equipo termociclador.

Figura 2. A. Electroforesis de ADN Genómico. Donde: Línea 1: PPM, 2: Soya, 3: Maíz, 4: Trigo, 5: Arroz, 6: Tabaco, 7: Plátano B. Electroforesis en gel $2 \%$. Resultados de la PCR. Donde: PPM: patrón ADN, B: blanco, 1: Soya C-IL1, 2: Maíz BT1507, 3: Maíz Fr-28 (control negativo).
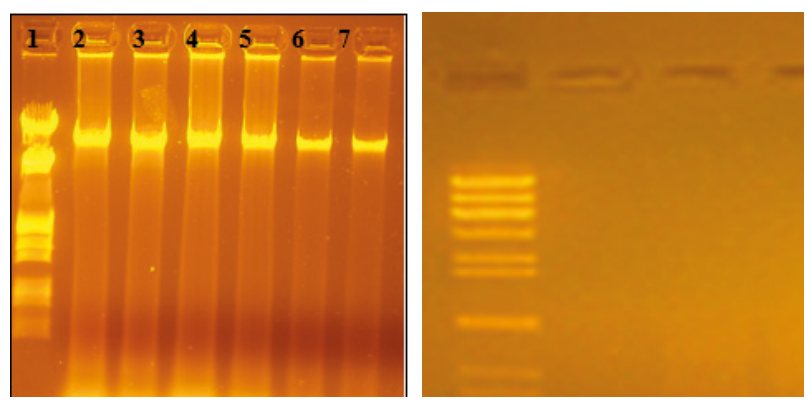

\section{Discusión de resultados}

De las soluciones de extracción diseñadas, se observa que los mejores resultados se obtuvieron con el método Z. Esto puede ser debido a la combinación del agente caotrópico Urea, que actúa sobre las interacciones intramoleculares no covalentes (puentes de hidrógeno, fuerzas de van der Waals e interacciones hidrofóbicas de macromoléculas) y al agente tensoactivo aniónico SDS; el cual forma micelas al interactuar con la membrana celular. Estas condiciones favorecen un aumento de la ruptura celular y por tanto, la exposición del ácido desoxirribonucleico al medio.

A partir de los resultados anteriores se procedió a comprobar la efectividad del método Z. Se usaron diversas matrices complejas, cuyas peculiaridades inhiben el proceso de extracción y purificación de ácido desoxirribonucleico, tales como: Soya en grano (presenta alto contenido de grasa vegetal), arroz en grano (presenta alto contenido de almidón), trigo en grano (presenta características comunes a diferentes matrices). Además, se emplearon segmentos de hojas frescas de plátano y tabaco, las cuales presentan alto contenido de agua y componentes enzimáticos, que afectan la calidad del ADN extraído.

Los resultados mostrados en la tabla 2 corroboran la efectividad del método seleccionado. Se obtienen elevadas concentraciones de ácido desoxirribonucleico, suficientes para realizar un análisis dePCR.Además, se evidencia que existe una correspondencia inversamente proporcional, entre la complejidad de las matrices y las concentraciones de ácido desoxirribonucleico extraído.

Tabla 2. Concentraciones de ADN, extraído de diferentes matrices, mediante el método Z.

\begin{tabular}{lll}
\hline Muestras & $\mathbf{n g} / \mathbf{u l}$ & $\mathbf{2 6 0 / 2 8 0}$ \\
\hline Harina de Maíz & $237.57 \pm 3.16$ & $1.92 \pm 0.13$ \\
Harina de Soya & $180.81 \pm 4.36$ & $1.87 \pm 0.19$ \\
Harina de Trigo & $209.84 \pm 5.48$ & $1.81 \pm 0.17$ \\
Harina de Arroz & $38.34 \pm 8.44$ & $1.86 \pm 0.27$ \\
Hojas de Tabaco & $55.26 \pm 11.5$ & $1.74 \pm 0.31$ \\
Hojas de Plátano & $79.49 \pm 14.1$ & $1.95 \pm 0.12$ \\
\hline
\end{tabular}


En la Figura 2 B se muestran los resultados de la electroforesis en un gel de $2 \%$; producto de la amplificación del $\mathrm{ADN}$, en el equipo termociclador. Las líneas 1 y 2 exhiben una banda de amplificación a la altura de $123 \mathrm{pb}$., del Patrón de peso molecular (PPM); lo cual corresponde con el peso molecular del segmento de gen amplificado (p35S). Sin embargo, al analizar las líneas B y 3 de la electroforesis, se observa que no hubo amplificación. Esto se debe a que en estas líneas se aplicaron respectivamente, el blanco de la reacción de PCR (no contiene ácido desoxirribonucleico) y el producto de amplificación de la muestra de ácido desoxirribonucleico de maíz No Transgénico Fr-28, el cual fue usado como control negativo del experimento. Cada uno de los controles positivos y negativos de la reacción de PCR; así como el resultado de la muestra blanco, fueron los esperados. Esto permitió, considerar como correcta los resultados obtenidos.

\section{Análisis de los factores económicos}

La determinación de los costos económicos, se realizó según se indica en materiales y métodos, donde:

$$
\begin{gathered}
\mathrm{CRM}(\mathrm{CTAB})=(\mathrm{CRC}+\mathrm{CRE}) / 250=(\mathrm{CRC}+ \\
(\text { Proteinasa } \mathrm{K}+\mathrm{CTAB}+\mathrm{ARNasa})) / 250 \\
=(508.76 \$+(366.62 \$+2.76 \$+ \\
147 \$)) / 250=1025.05 / 250=\underline{\mathbf{4 . 1} \$} \\
\mathrm{CRM}(\mathrm{Z})=\mathrm{CRC}+\mathrm{CRE} / 250=\mathrm{CRC}+ \\
(\mathrm{UREA}+\mathrm{SDS}+\mathrm{ARNasa}+\mathrm{AcNH} 4) / 250 \\
=(508.76+(5.98+0.887+0.27 \\
+14.7)) / 250=530.59 / 250=\underline{\mathbf{2 . 1 2} \$} .
\end{gathered}
$$

Mediante el análisis de los resultados anteriores, se pudo determinar que la aplicación del método Z, permite la obtención de ácido desoxirribonucleico de calidad amplificable, con un costo inferior a $0.5 \$$ por cada muestra analizada, respecto al método CTAB. Lo cual significa un ahorro económico de un $48.3 \%$ y una alternativa al uso del método CTAB, para la extracción/purificación de ácido desoxirribonucleico, proveniente de diferentes matrices.

\section{Conclusiones}

Los métodos diseñados permiten extraer/ purificar ácido desoxirribonucleico a partir de muestras de alimentos. Sin embargo, es el método Z (SDS, NaCl, Tris-HCL, EDTA, Urea) el que brinda mejores resultados, respecto al método CTAB usado como referencia. Mediante la aplicación de este método (Z), se logra un ahorro económico de $48.3 \%$; equivalente a $0.5 \$$ por cada $100 \mathrm{mg}$ de muestra analizada. Además, se obtuvieron concentraciones adecuadas de ácido desoxirribonucleico, en muestras con elevado contenido de carbohidrato (arroz, plátano, tabaco) y grasa vegetal (soya).

\section{Referencias bibliográficas}

Anklam E., Gadani F., Heinze P., Pijnenburg H., Van den Eede G. (2002). Analytical methods for detection and determination of genetically modified organisms in agricultural crops and plant-derived food products. European Food Research and Technology 214: 3-26.

Bartlett \&Stirling (2003) Short History of the Polymerase Chain Reaction, in: Methods Mol Biol. 226:3-6. 
Corbisier P., Broothaerts W., Gioria S, Porcar M., Ramos S., Larrote A. 2007. Short Schimmel H., Burns M., Baoutina., et al. (2007). Toward metrological traceability for DNA fragment ratios in GM quantification. Effect of DNA extraction methods on the quantitative determination of Bt176 corn by real-time PCR. J. Agric. Food Chem. 55: 3249-3257.

Holst-Jensen, A.; Rønning, S.; Løvseth, A. y Berdal, K. G. (2003). PCR technology for screening and quantification of genetically modified organisms (GMOs). Anal. Bioanal Chem. 375: 985-993.

Communication. A simple DNA extraction method suitable for PCR detection of genetically modified maize. J. Sci. FoodAgric. 87: 2728-2731.

Roux, K.H. (1995). Optimization and troubleshooting in PCR. PCR methods and applications 4., 185-194.

Rott, M., Laerence, T., Wall, E. and Green, M. (2004). "Detection and Quantification of Roundup Ready Soy in Foods by Conventional and Real-Time Polymerase Chain Reaction". J. Agric. Food Chem. 52: 5223-5232.

Jasbeer K., Son R., Mohamad F., Cheah Y. K. (2009). Real-time PCR evaluation of seven extraction methods for the purpose of GMO analysis. International Food Research Journal. 16: 329-341

Mullis K. The unusual origin of the polymerase chain reaction. Scientific American. 1990:262:56-61, 64-5.

Margarit E., Reggiardo M.I., Vallejos R.M., Permingeat H.R. 2006. Detection of Bt transgenic maize in foodstuffs. Food Research International. 39: 250-265.

Núñez, L. Detección y ensayo de los organismos genéticamente Modificados. Revista Cubana Alimentación y Nutrición. 2011;21(2):293-302.

Ovesná J., Kučera L., Hodek J., Demnerová K. 2010. Reliability of PCR based screening for identification and quantification of GMOs. Czech J. Food Sci. 28: 133-138.

Tripathi L. (2005). Techniques for detecting genetically modified crops and products. African Journal of Biotechnology. 4: 1472-1479.

Tozzini, A. C. (2004). Detección de OGM en la cadena alimentaria. Biotecnología y Mejoramiento Vegetal. INTA. Buenos Aires, Argentina. Disponible en: www. biblioteca. org. ar/libros/150439. pdf, 409-424. 
